\title{
11 Jus ad vim
}

\section{War, peace and the ethical status of the in-between}

\author{
Nicholas Melgaard and David Whetham
}

\section{A good crisis}

"Never let a good crisis go to waste" has been attributed to different political leaders at different times, in different political circumstances. The difficulty in crediting this aphorism is probably evidence of its near universal applicability. Opportunistic coercive activity that falls through the cracks between war and peace, is the subject of this chapter. Political actors can use significant events within or between countries to circumvent normal barriers. While attention is focused on a major issue elsewhere, it creates opportunities for action in areas that would normally have a much higher transaction cost for getting involved. The world looks left; some cunning political actor moves right.

The COVID-19 pandemic has been one such unwasted crisis. Russia and possibly China seem to have done just this with the recent coronavirus pandemic. ${ }^{1}$ Reports quickly spread of the large-scale, coordinated state-supported effort to amplify division, spread misinformation, undermine trust in national and international responses (Rankin 2020). A campaign began by simply amplifying the disinformation that an open society was perfectly capable of creating itself. But this was then developed into a focused attempt to hack the labs creating a vaccine for information about its storage and distribution protocols (Corera 2020). The direct goal might not have been the loss of life. Still, the entirely predictable effect of such actions will be the undermining of public confidence in a necessary health initiative. The indirect result could certainly be an increase in deaths.

Oscar Jonsson (2019) argues convincingly that the Russian government sees war and peace not as binary states but as a spectrum, with information warfare now being capable of achieving political goals commensurate with war (Jonsson 2019). With this in mind, Gary Corn (2020) discusses in a recent article how Russia hates to waste a crisis (Corn 2020). He summarises, "Information operations are a key component of Russia's strategy for confronting Western democracies, and covert deception and disinformation form the core of its active campaigns". Yet another modern actor to whom our ancient aphorism could credibly be credited.

The sowing of controlled chaos, promotion of dissension and disorder: these are not incidental effects, but rather consciously deployed instruments aimed at the weakening of trust within society and the undermining of its domestic institutions.

DOI: $10.4324 / 9781003164197-16$ 
They target the faith and confidence between societies, and the international institutions that have supported the cooperation that has underpinned the flourishing of the West since the end of World War II. Russia's actions aren't about defeating the West. The intention is to weaken it and level the playing field. Perhaps then, Global Russia will be able to reassert itself.

An important question then arises. Brutal as it is, we have an appropriate ethical framework for dealing with the traditional means of warfare. The just war tradition, a constantly evolving body of thought seeking to enable structured ethical discussion at the very extremes of human behaviour, has been developing since antiquity. But we have next to no specific ethical framework to deal with this other kind of subversive political activity. What rules should govern a response to dishonest coercive opportunism? In this case, we might ask what level of sub-war threshold political activity we are willing to find "acceptable", or at least, what do we recognize as falling short of an "armed attack", permitting us to cross the threshold into war ourselves as a response? If not war, what is the appropriate response to information- and communication-based threats? What are we morally permitted actually to do?

\section{Why does it matter?}

It would be a mistake to consider the Just War a purely Western Tradition. Still, in the form it is most often framed, it is a synthesis of classical Greco-Roman and later Christian values (Johnson 1981). It also embraces a way of thinking that results in a "common language for discussing and debating the rights and wrongs of conflict" (Whetham 2010, 65). The just war tradition provides guidance on what is acceptable, and (most importantly) not acceptable, even in times of war. It states that there should be limits on when the use of force can be considered legitimate (the jus ad bellum), and that there should also be limits on what and whom that force can be directed against (the jus in bello).

Fundamentally, this way of thinking assumes that there is a difference between the situation of war and the situation of peace. This is very important to the present discussion. The "declaration by a legitimate authority" is considered so important, not just because of the need to ensure one has the right to wage war, but the declaration element signifies a political community's move from one understanding of context to another. The new context permits one to do things that one would otherwise not be allowed to do. This includes, of course, the deliberate taking of human life as an extension of the idea of collective self-defence. This is the apex of ethical discussion in armed conflict; the reason why some things are allowed in war that would be unthinkable in peace. The ad bellum determination means that such acts can be engaged with on behalf of one's community. The fact that plans to do this can be premeditated and formulated in advance shows the difference between this and the peace-time actions of a police officer responding to a call out and forced to draw their weapon when the bank robber turns out to be armed. One might be permitted to arrest someone in peacetime, but one is not supposed to set 
out with the intention of killing them before one even leaves the police station. Not so in war.

At least the police officer knows the context she is operating in. In the same way, military staff officers planning a military operation are generally clear whether their planning assumptions are based in the context of an international armed conflict, non-international armed conflict or some kind of peace support mission in which the use of lethal force is still generally considered as an available option. But where do state-sponsored hostile information operations that can result in indirect harm, or even death, sit in this understanding? Robert Gates, US Secretary of Defense, describes (2009) this ambiguity very unambiguously: "the categories of warfare are blurring and no longer fit into neat, tidy boxes" (Gates 2009).

So what are our options? As much as we would like to see "the West" as ethically principled, this is naturally an area in which our own state wishes to act as well. Of course, it must do, and not only in a purely defensive role. The fact that such measures are technically "non-violent" and less immediately risky than "boots on the ground" must count towards their attractiveness.

The first option is that we can choose to apply the exceptional permissions afforded by a state of war by acting as if we are in a state of constant conflict, with everything that goes along with this. The second is that we can limit our responses to the peacetime model of permissible action and address the threats as criminal activities rather than as acts of war. ${ }^{2}$ This latter response has some credibility, at least in terms of providing a clear framework to the problem. One should expect the police to deal with such threats, gather evidence and hand it over to the prosecutors to make the decision to charge in a court or not. In the case of actors not based in the same territory where harmful actions have taken place (where a domestic court is not suitable), issues are raised through diplomatic channels and demands made for the relevant jurisdiction to prosecute those responsible. In the case of disinformation, this could either be dealt with as an "incitement to xxx" type charge, or perhaps as a civil defamation case, dealt with through the civil courts (with the risk of damages being payable if the issue is found to be proved on the balance of probabilities). ${ }^{3}$ Of course, this sort of thing takes a great deal of time. The results may simply be ignored. Or foreign jurisdictions able to act might simply decide not to. ${ }^{4}$ It might then be up to the politicians to choose what to do through diplomatic channels, with powerful states being able to mobilize international public opinion in the form of collective political or economic sanctions. Or they may not. What is certain is that while it is possible that something on this range of actions might conceivably act as a deterrent to the behaviour occurring in the first place, being unable to respond in kind, or even threaten to do so because one would be breaking the same laws, makes deterrence lack a large element of its necessary credibility.

Countering such behaviour within one's own peacetime rules will possibly therefore be inadequate. Peacetime laws are supposed to protect people from harm, not give them permission to harm others. Special permissions are needed to allow harm to be inflicted. Self-defence can justify inadvertently hurting a mugger 
who is assaulting an old lady, for example. But extending the idea of self-defence to permit such activity in a third-party state is effectively moving the framework of understanding from the individual-based rights and permissions of peacetime, to the collective self-defence ideas inherent in wartime.

To see such behaviours as causing harms commensurate with armed conflict, thus warranting a war-like response, certainly carries with it a better chance of deterrence. But is it really war? Thomas Rid (2012) prefers to see this kind of "sub-war" activity as "neither crime nor war, but rather in the same category as subversion, spying or sabotage, existing somewhere on the spectrum between apolitical crime at one end and genuine war at the other" (Rid 2012, 7). This seems to echo the understanding (or at least practice) of the Russian state. If the traditional binary - war versus peace - conception is no longer appropriate, and one chooses to try and understand contemporary conflict as more like a spectrum of activity, how does this help us answer the question regarding what we are actually morally permitted to do on this spectrum?

\section{Jus ad vim}

There is a view that the "consensus behind just war theory is slowly beginning to wane and the relevance of the theory gradually eroding". Jai Galliot (2019) comments that due in part to the changing means of political control, many "have begun to find that there is a limit to the extent to which the traditional principles and usual rules of war found in just war theory .... can be stretched to cover modern conflict". Such a range of conflicts includes the very different environments of Vietnam, Afghanistan, Iraq, Libya and Syria. Galliot focuses on a discussion of "kinetic" (violent) force in periods of ill-defined, fluid armed conflict, yet the idea is the same for political, information-based action. Such cases, Galliot observes "tend to focus on individual rather than categories of people and involve the employment of emerging military technologies", they are "somewhat resistant to moral evaluation within the state-centric framework of the traditional just war theory" (Galliot 2019, 3-4). When the subject of power becomes so individualized, the traditional context-based justification of wartime behaviour becomes very difficult to sustain.

Still, the reasons why such ideas of jus ad vim have taken hold are not difficult to understand. According to Brunstetter and Braun in their highly influential paper in 2013 responding to the outlining of the idea by Michael Walzer, jus ad vim activity is just "nominally easier to justify". Ad vim measures require less of a commitment from politicians and statesmen than measures that clearly fall above the war threshold, but still permit you to do more than in the domestic peacetime context (Brunstetter and Braun 2013, 88). It has been popular because there is a gap in the ethical market for clear and consistent scaffolding to provide structure to decisionmaking below the threshold of traditionally understood armed conflict, whether this is a raid, surgical strike, drone attack or subversive information campaign.

Rather than accepting that all legitimate warlike actions can be justified because one's political community have determined that the ad bellum criteria have been 
satisfied (i.e. one's state is now at war), ad vim requires that each specific nonpeaceful act is assessed against the ad bellum criteria on its own merits. Does the specific act have a just cause related to an injury or harm received or threatened; does the individual or institution carrying out the act have sufficient authority and have they declared why they are responding in such a way; is it the real reason why one is seeking to act, that is does the actor have the appropriate intention; is the response proportionate to the injury suffered or threatened; will the action have a reasonable prospect of being successful and finally, has everything else that might work within the normal range of actions (domestic law, diplomatic sanctions etc.) already been attempted?

If these criteria can be met, the act itself may be permitted, but how is one to carry it out? If one were to accept this new category, the next natural step would be just applying the ethical framework for activity in bello to such sub-threshold behaviour. In bello rules already specify who and what may be made the object of attack and to what extent. While the spectrum of activity is potentially broad and can cover everything from kinetic attacks through to non-physical information operations aimed at shaping actions or perceptions, in theory at least, the same in bello rules could apply, supplementing the ad bellum principles so they are taken all together for each act. In that respect, "changing weapon systems does not change the moral demands on those operating the systems" (Skerker 2021). The rights of those being targeted, and those who will be affected even if not directly targeted, still need to be taken into account.

However, simply transferring the existing rules from a state of declared war is not as viable as it at first might sound. For example, Brunstetter and Braun (2013) argue that the principle of "last resort" simply does not make sense transferred from an ad bellum to an ad vim context because it is war itself that is the last resort rather than the type of behaviours that fit here - these are the steps that are being tried before the last resort of war itself (Brunstetter and Braun 2013, 97). They are also concerned that the principle of proportionality may inadvertently permit escalation - something that goes against the very reason why politicians may choose to act in this area in the first place. One of the attractions for operating in this area is precisely because the actions do not cross the war threshold or pitch one's country into a state of armed conflict. If this consideration is ignored, then action taken may very quickly escalate resulting in open hostilities (Brunstetter and Braun 2013, 98). The point for policy makers is to be able to act and respond in this area within an ethical framework that can guide appropriate behaviour, without resulting in the kind of large-scale harms that war almost inevitably involves.

Brunstetter and Braun ask, "what would a theory of jus ad vim that counters the shortcomings of the jus ad bellum framework in this context look like?" (Brunstetter and Braun 2013, 88). These revised principles for jus ad vim and in bello can also then be used for other "non-kinetic" means as well (Lupton 2019). Their solution is to "recalibrate" jus ad bellum criteria by adding a new principle, the probability of escalation. Their argument is that a similar set of rules should be employed in sub-threshold conflict, but with the addition that the 
risk of escalation ought to be minimized. This is a completely understandable step to take. Given sub-threshold conflict remains outside the boundaries of allout war, the potential for a crisis to develop is a key consideration, whereas this might cease to be relevant if and when a situation of all-out war has already been accepted. However, for the reasons that we set out in the following, we think this recalibration does not solve things in the way intended.

\section{Jus ad vim, categories and shifting contexts}

Our first concern is that such an articulation is incomplete. Avoiding escalation alone surely does not imply moral equity. For example, if I am a vastly superior state, I could probably guarantee that the other weaker state I am bullying will be too fearful to retaliate, at least directly. Therefore, while there may be proxy actors or tools that can provide an element of deterrence, there may in fact be very little chance of escalation from their side. This surely does not mean that I am more justified in this behaviour.

More generally, the issue with Brunstetter and Braun's argument is that it implies that everything is ok so long as the situation does not escalate. They accept that escalation is not always a worse course of action, and increased coercion is not always immoral, but argue that ensuring that any ad vim action does not lead to the outbreak of war is "essential" (Brunstetter and Braun 2013, 99). We believe this represents fundamentally a frustrating aversion to confrontation for its own sake, and an unwillingness to accept that confrontation in one form or another might actually be more ethically viable than its alternatives. War is, after all, permitted as a last resort in the just war tradition only when the evil it is seeking to avert or turn back is genuinely considered to be worse than that of war itself. Without this acceptance that war may sometimes be (although admittedly rarely) the least-worse option, we see the "pacificism by other means" argument often levelled against modern revisionism apply in a similar way. If there is a starting prejudice against confrontation in any circumstances, then the inertia of any variation of Just War theory built on its foundations will always drag it towards pacificist inactivity. While attempting to prevent escalation may indeed be entirely appropriate, prudent and ethical in many or even most situations, when considering the importance of deterring harmful behaviours, to have a principle that prohibits acts that might lead to escalation seems the equivalent of publicly ruling out ground troops from a planned military intervention. ${ }^{5}$ An act that demonstrates a lack of resolve and signals a lack of willingness to back up one's actions with the necessary commitment to be able to see it through is likely to be shrugged off by any opponent who is willing to bear the stated limited costs one is willing to impose.

We believe that this problem comes from seeing jus ad vim as an attempt to provide a new category of moral decision-making in the ambiguous murky world that sits below the threshold of all-out war, but above peace. We use the terms "below", "above", "threshold", "phase" to talk about these forms of war. But we might just as easily use "outside" or similar, as the principle is that these cases do not share 
the agreed upon context of being in a state of war. The concept of jus ad vim suggests that measures such as surgical strikes, limited force, information campaigns and other forms of limited coercion fall into a third category. As such, they are subject to rules that are different to those that pertain in either peace or war.

Our issue with this is that it is trying to solve the difficulty of switching between categories by creating another category. For "category" we might also read "context". The problem is not that the contexts or categories we use to judge certain behaviours have ceased to be "fit for purpose" (to use a military expression). The problem is our insistence on judging behaviour based on contexts and categories. Any such moral theory will be doomed to failure as real world circumstances inevitably develop. Indeed, our reluctance to accept a new threshold as a solution to tired and irrelevant old thresholds is in large part due to why such measures are so frequently employed. It is precisely because they fall outside the recognized social conditions of "war" that surgical strikes, or COVID-related misinformation for that matter, have become so popular. A whole set of expectations and legal parameters exist on either side of this line. Valerie Morkevicius and Danielle Lupton (2019) comment that: "one reason just war principles may be subject to political abuse is that the concept of war itself is treated as a binary concept by contemporary just war thinkers" (Lupton 2019, 36). As Jonsson argues earlier, the challenge that we are faced with today is that our competitors do not recognize that line, or have deliberately circumvented where we have chosen to draw our own lines. New categories will simply inspire a new wave of the same kind of creative categorization that got us to this discussion in the first place.

\section{Rephrasing the challenge}

The alternative to drawing category distinctions is to accept that contemporary conflict can be better understood as a spectrum. Along with Rid (above), and apparently, conforming with "the Russian way of war", Morkevicius and Lutpon find that "the insights from the field of international relations make it clear that war, as it is traditionally understood, is actually a location on a broader continuum of political violence" (Lupton 2019, 52). This would suggest that a sliding scale of what you are permitted to do along a spectrum would be more useful for determining the appropriate ethical guidance (Garraway 2008).

The Just War framework "is about exceptions", providing a structure for figuring out when you can do things you are not otherwise allowed to do. ${ }^{6}$ The "exceptions" of wartime behaviour are justified by reference to a change in context: between war and peace. When one's political community determines that this status has changed, it means that previously prohibited acts can now be entertained. The declaration of war is a community's articulation and recognition of a new and exceptional context. As such it is a social construct rather than an objective point that can be definitely observed. ${ }^{7}$

But as we have already seen, its principles are useful beyond this very specific context as well. When applied to situations where the political community has not accepted the change from peace to war, the ad bellum rules remain useful for 
determining when exceptions can be made, and if they can, the in bello rules can still guide us into what we may do, or how far it is permissible to go. Do they need any help? We have already rejected the anti-escalation consideration earlier. Is that because we believe the combination of the two sets of criteria are genuinely sufficient on their own? We think that this may indeed be the case. Given the extremely long pedigree of the testing of those criteria, and the way they embrace a combination of absolute deontological requirements, while demanding considerations of both consequential and prudential factors, we believe it may simply be a matter of emphasis rather than the creation of new criteria.

Rather than being a "state-centric framework", no longer appropriate for an age of non-state and sub-state actors (Galliot 2019, 3-4), we would argue that the just war tradition predates the modern, state-based system by some two thousand years. ${ }^{8}$ Its criteria have evolved over that time and have been applied to the wars of nation-states just as they were applied to the conflicts of city states, princedoms and empires in the middle ages. ${ }^{9}$ While the way we need to apply them must adapt to the changing character of war, we hold that the overlapping criteria remain remarkably robust for determining when an exception may be made in many different situations, not just war.

The greatest challenge is not the criteria themselves, but that they have evolved over several millennia to give us a framework for determining these exceptions and in the process been given the collective title of "the just war tradition". But that does not mean that the criteria are only useful in that context - the same types of reasoning can be applied to any situation in which one is seeking to do something normally prohibited. It could therefore be usefully thought of as a "Just Exception Tradition".

Take for example a "citizen's arrest". Normally, one cannot hold another person against their will, but there are certain exceptional instances where one can reasonably curtail someone's liberty. In the United Kingdom, detaining someone against their will is itself a criminal offence, but the right to do this has been in common law for centuries under certain circumstances. ${ }^{10}$ While we are less interested in the legal articulation, the key thing here is the ethical principles that underpin this long understanding of when it is permissible (but never required) to break one rule in order to uphold another. There is a seriousness threshold that must be considered (just cause leading to delegated authority to act). You must also believe at the time (right intention) that it is not reasonably practicable for a police officer to perform this task (last resort), and that the action is genuinely necessary to prevent (reasonable prospect of success) a specific person (discrimination): causing physical injury to themselves or any other person; suffering physical injury; causing loss of or damage to property or making off before a constable can assume responsibility for them (macro proportionality).$^{11}$ Anyone attempting such an arrest must inform the subject why they are being held (declaration) and what they are suspected of (the just cause again). Obviously, one can't use more force to do this than is considered reasonable in the circumstances (proportionality): "So, one can physically restrain a thief, but one cannot rape him; read his diary; or prevent him from voting" (Skerker 2021). One can find oneself in 
serious trouble if the exceptional criteria are not met - for example, you could be found guilty of false imprisonment, and/or assault.

What are the contextual factors that need to be taken into account when seeking to defend the state and its citizens against hostile intervention? All of the Just War criteria overlap and must be considered as a whole rather than as andividual checklist, and while this is a subject that needs much further attention, here we look at two criteria in particular as they have already been discussed earlier - last resort and proportionality - as well as the role of discrimination and intention.

We think that, just as the other criteria need to be understood in context, the last resort criterion does still make sense even if one is not determining if the threshold to declare war has been crossed. War itself is the last resort when one is thinking about the former, but in this case, we are actually asking if there are any measures that don't require exceptions to be made that might work but haven't yet been tried. For example, Walzer prudently suggests that nonlethal policing actions, akin to what must be undertaken in zones of peace, should be prioritized first (Walzer 2007, 482). Only if these have not worked should the exception be made to permit the type of actions normally prohibited in peacetime. This is necessary precisely because the blanket permissions granted by a state of war do not exist.

While Brunstetter and Braun (and many others) are uncomfortable with the traditional criteria of proportionality, which can be seen as a "nebulous and indeterminate constraint" (Brunstetter and Braun 2013, 98), we think that it can still be extremely valuable. In war we know that what is at stake is a significant factor in determining what is justifiable. While some things remain forbidden regardless of context, there are some things that will change as the stakes get higher. For example, in a war of national survival, it may be permissible to cause more harm to those who have not made themselves liable to harm - that is non-combatants as a foreseeable but undesired side effect of one's actions directed towards your state's survival, than if one were engaged in a very limited peace enforcement mission in which the aim is to get humanitarian assistance to those in desperate need. In such a situation, it would seem

inappropriate and even perverse to move the burden of risk on to that same population, accepting a high degree of collateral damage, for example, in an effort to minimize one's own casualties when the very purpose of being there is to protect those people who are now being put at additional risk.

(Whetham 2010, 83)

We agree with Brunstetter and Braun that, on the whole, discrimination must be applied in an even stricter sense than at the ad bellum level. But, this is to do with where on the conflict spectrum this activity is likely to be placed - what is at stake - rather than because it is happening in a different category of activity. Returning to the sliding scale/spectrum understanding of conflict mentioned earlier, this may require the sacrificing of individual rights to protect even more people, even if there is no declared state of war. For example, averting a nuclear 
terrorist threat against a whole city might require some civilians to be put at risk of harm or even death. This may be true regardless of whether it takes place during declared hostilities or not. To prohibit the exception because the category is wrong is to fail the test of protecting one's people. As such, the spectrum is what is important, not the artificial category. This also has implications for the application of proportionality at the in bello level.

Finally, we agree with Brunstetter and Braun about the essential importance of intention. We think the emphasis here is of particular importance for the way that the in bello criteria of discrimination and proportionality are to be understood in this different context. We accept (as did the medieval scholars who debated these ideas 1000 years before us) that intention shapes the moral and physical quality of action, so there is a direct link between intention and the normal in bello criteria limiting who may be intentionally harmed and to what extent. ${ }^{12}$ Right intention must be directed towards upholding the rights of the Other (Skerker 2021).

Directing an information attack against an agent of a hostile state causes no problems in wartime, and an exception can easily be justified if the stakes are sufficiently high outside of wartime. Creating a martyr by manipulating the social media of a regular civilian with no direct connection to the hostile acts being perpetrated by their state, in order to get that person arrested or killed (so their cause can be highlighted and used as a way to manipulate public opinion and ultimately change their government's policy) would be to go far beyond what was permitted. While one could perhaps justify the in bello considerations in terms of "it's not us doing the bad things to them - it's their state", this would be using the targeted person as simply a means to an end. One cannot escape moral responsibility by claiming that the result was foreseeable but unintended if the suffering is a required and intended part of the effect one is seeking.

In a broader sense though, right intention shapes more than the relationship with a specific target. Intentions do matter, and the idea of returning to the status quo ante bellum is very different from aspiring to return to something more positive. War must not be characterized as a return to anything. It seems almost impossible to make moral arguments if this is the case.

Our point in essence is that war and conflict must be justified as an activity towards an eventual improvement if it is to be justified at all. Simply restoring the ante-bellum conditions that led to the outbreak of war is a rather depressing justification for all the suffering and bloodshed it would involve. The belief that things cannot gradually get better is at once a belief in the inevitability of war, and at once a belief that we have no power to prevent it. The premise that war arises as an aggregate of human decision-making seems indisputable, however complex a social phenomenon the origins of a given war might be. The idea that we exercise choice to go to war, and can choose how we behave whilst fighting is surely the most basic premise of the just war tradition. Any form of moral discussion requires this. To claim that war is inevitable, but also concede that war is fundamentally a result of choices (and thus subject to moral discussion), is a totally incompatible pair of beliefs to hold. One must admit that a given conflict rests on human choices, we have some relevant moral agency, war is not inevitable, and 
therefore things can indeed improve. Any moral decision-making in the context of conflict must at least acknowledge the possibility of things improving over time.

As such, just as acts of perfidy are prohibited because they undermine the essential faith in the rules themselves (Whetham 2009, 6), actions that destroy the foundations of knowledge or damage the long-term social cohesion even of a currently hostile state cannot be justified. It is impossible to see how this type of action, even if successful in undermining the will of an adversary, can actually lead to a better situation in the long run when the situation is viewed as a whole. In the same way, the just war tradition has long accepted that while it is acceptable to take the food or crops necessary for the subsistence of troops, it is never justified to destroy the means of making any more. For example, Deuteronomy $(20: 10,19)$ forbids the destruction of fruit-bearing trees. "Condemning the civil population to starvation was hardly a way of promoting long-term reconciliation” (Whetham 2010, 69).

\section{Conclusion}

Let us return to the case of "sub-threshold behaviour". We might ask whether act of political subversion, such as undermining another country's COVID response, was indeed an act of war. The transmission of information was being deliberately obscured and undermined by an external actor. However, the question of whether this counted as an "act of war" merely serves to buy into an episodic, contextbased set of justifications that are clearly not relevant anymore. It is not that there is a different and more satisfying answer to the question of when the balance tips over into a state of war, from a state of peace; the entire convention of justifying behaviour according to contexts and states is unviable.

Those who say this unacceptably blurs the distinction between war and peace are, unfortunately, disconnected from the current reality on the ground. One cannot simply lament that the reality doesn't fit the socially constructed theory so, therefore, reality must change. It is up to a state or representative political community to determine if it is in a declared state of war or not, but the fact that harms can be deliberately committed against it without that state wishing to make such a declaration does not mean that it is only able to act using the tools of peacetime. Creating a new category between peace and war is one way of doing this, but for the reasons that we have set out earlier, we do not think this new category really solves the problem without creating new ones. Instead, we suggest that actions that go beyond the normally permitted may be justified as exceptions if they can satisfy the ad bellum and in bello reasoning we are already familiar with, with a special emphasis placed upon the intention criteria when considering the full ramifications of the proposed act.

In practice, our Just War position would focus less on consequentialist-based arguments aimed at working within one context or shifting to another. The value of declarations of war and victory parades in such cases serves to demarcate these shifts in context. Without them we are left with the ad vim problems mentioned earlier. Instead, the moral foundations of our position rest on a faith in the possibility of gradual progress towards peace. If this is not accepted as a possibility, 
it becomes hard to have any moral discussion relating to armed conflict. Once this is taken as a foundational premise, individual actions are justified deontologically if they represent activity in the service of this progress.

When faced with political or information-based subversion, the discussion of whether this fits into the neat categories of war, peace or a third category is a moot point. Not even traditionally understood wartime behaviour fits into the neat categories of war and peace anymore. Nothing is solved or rescued simply by adding an intervening level. We might ask instead whether information-based attacks represent a credible source of harm, and whether they can be met with similar measures in response according to a framework within which deontological concerns based on an appreciation of human rights are respected. The answer to the first is "yes, absolutely". To the second, "yes maybe". Much more thinking is required in this area. While the reasoning inherent in the just war tradition may be a useful guide in a much wider range of situations than initially presumed, and can assist us with that necessary thinking, the discussion of jus ad vim must not be a discussion of how we continue to prop obsolete ideas up, but rather to assess the foundations upon which they are grounded.

\section{Notes}

1 For example, Rankin (2020) and The Soufan Centre (2020).

2 Of course this works both ways, and we would either have to limit our own responses to the area of legally permissible activity, ignore the rules ourselves or create some kind of legal fiction behind which we can hide - a move that makes taking the moral high ground rather awkward.

3 The balance of probabilities rather than beyond reasonable doubt is the bar in civil cases, at least in the UK.

4 We can't help thinking about the South African diplomats in Lethal Weapon, invoking "diplomatic immunity" each time they are about to be apprehended.

5 We are thinking of Kosovo in 1999 here, but there are other supposedly straightforward conflicts that were hampered by early declarations of red lines for domestic audiences that signalled limited commitment to adversaries at the same time.

6 A similar argument is made by Lucas (2015).

7 We accept that there may be situations in which a political community or state is objectively being attacked, such as when it has been subject to a surprise nuclear strike, even when it does not know from where the attack has come. This raises an interesting situation in which a state might be at war, but not sure whom it is at war with. See Whetham (2016).

8 If one takes that starting position to be the familiar 1648 Treaty of Westphalia.

9 See Whetham (2009).

10 The current laws are set out in Section 24A of the Police and Criminal Evidence (PACE) Act 1984.

11 In the UK, such an offence needs to be of a seriousness that carries a potential prison sentence of over 6 months imprisonment.

12 See Chapter 2 of Whetham (2009).

\section{References}

Brunstetter, Daniel, and Megan Braun. 2013. "From Jus ad Bellum to Jus ad Vim: Recalibrating Our Understanding of the Moral Use of Force”. Ethics \& International Affairs 27 (1). 
Corera, Gordon. 2020. "Coronavirus: Hackers Targeted Covid Vaccine Supply 'Cold Chain”". $B B C$, December 3. Accessed February 1, 2021. www.bbc.co.uk/news/technology55165552 .

Corn, Gary. 2020. "Coronavirus Disinformation and the Need for States to Shore Up International Law". Lawfare, February 4. Accessed February 2, 2021. www.lawfareblog. $\mathrm{com} /$ coronavirus-disinformation-and-need-states-shore-international-law.

Galliot, Jai. 2019. Force Short of War in Modern Conflict. Edinburgh: Edinburgh University Press.

Garraway, Charles. 2008. "The Relevance of Jus Post Bellum: A Practitioner's Perspective". In Jus Post Bellum: Towards a Law of Transition From Conflict to Peace, edited by Carsten Stahn and Jaan K. Kelffner. The Hague: Asser Press.

Gates, Robert M. 2009. "A Balanced Strategy: Reprogramming the Pentagon for a New Age”. Foreign Affairs, January/February. Accessed February 1, 2021. www.foreign affairs.com/articles/united-states/2009-01-01/balanced-strategy.

Johnson, James T. 1981. The Just War Tradition and the Restraint of War. Princeton: Princeton University Press.

Jonsson, Oscar. 2019. The Russian Understanding of War: Blurring the Lines between War and Peace. Washington, DC: Georgetown University Press.

Lucas, George R., and David Whetham. 2015. "The Relevance of the Just War Tradition to Cyber Warfare". In Cyber Warfare: A Multidisciplinary Analysis, edited by James Green. Abingdon: Routledge.

Lupton, Danielle, and Valerie Morkevicius. 2019. "The Fog of War: Violence, Coercion and Jus ad Vim”. In Jus Ad Vim, edited by Jai Galliott. Edinburgh: Edinburgh University Press.

Rankin, Jennifer. 2020. "Russian Media Spreading COVID Disinformation". The Guardian, March 18. Accessed February 1, 2021. www.theguardian.com/world/2020/mar/18/ russian-media-spreading-covid-19-disinformation.

Rid, Thomas. 2012. "Cyber War Will Not Take Place”. Journal of Strategic Studies 35 (1).

Skerker, Michael. 2021. "The Rights of Foreign Targets in Cyber Operations". In Cyber Warfare Ethics: A Handbook for Military Professionals, edited by Michael Skerker and David Whetham. Havant: Howgate.

The Soufan Centre. 2020. "Russia Exploits Coronavirus as New Opportunity to Spread Disinformation". Accessed February 2, 2021. https://thesoufancenter.org/intelbriefrussia-exploits-coronavirus-as-new-opportunity-to-spread-disinformation/.

Walzer, Michael. 2007. “On Fighting Terrorism Justly”. International Relations 21.

Whetham, David. 2009. Just Wars and Moral Victories: Surprise, Deception and the Normative Framework of European War in the Later Middle Ages. Leiden: Brill.

- 2010. "The Just War Tradition: A Pragmatic Compromise". In Ethics, Law and Military Operations, edited by David Whetham. Basingstoke: Palgrave Macmillan.

_. 2016. “'Are We Fighting Yet?' Can Traditional Just War Concepts Cope with Contemporary Conflict and the Changing Character of War?". The Monist (99). 